\title{
Correction to: The eagle sign: a new preoperative MRI-based tool for predicting topographic correlation between craniopharyngioma and hypothalamus
}

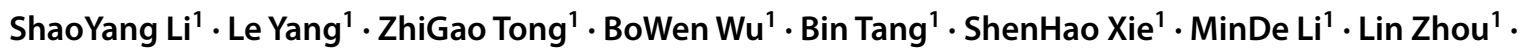 \\ ChenXing Ouyang ${ }^{1} \cdot{\text { Xiao } \mathrm{Wu}^{1} \cdot \text { YouQing Yang }}^{1} \cdot$ ChunLiang Wang ${ }^{1} \cdot$ Tao Hong $^{1}{ }^{1}$
}

Published online: 2 December 2021

๑) Springer-Verlag GmbH Germany, part of Springer Nature 2021

\section{Correction to: Journal of Cancer Research and Clinical Oncology \\ https://doi.org/10.1007/s00432-021-03791-4}

In the original article, the Fig. 1 is published incorrectly. The correct Fig. 1 is given below.

The original article has been corrected.

The original article can be found online at https://doi.org/10.1007/ s00432-021-03791-4.

ChunLiang Wang

wclac0249@126.com

$\triangle$ Tao Hong

ht2000@vip.sina.com

1 Department of Neurosurgery, The First Affiliated Hospital

of Nanchang University, 17 Yong Wai Zheng Street,

Nanchang, China 

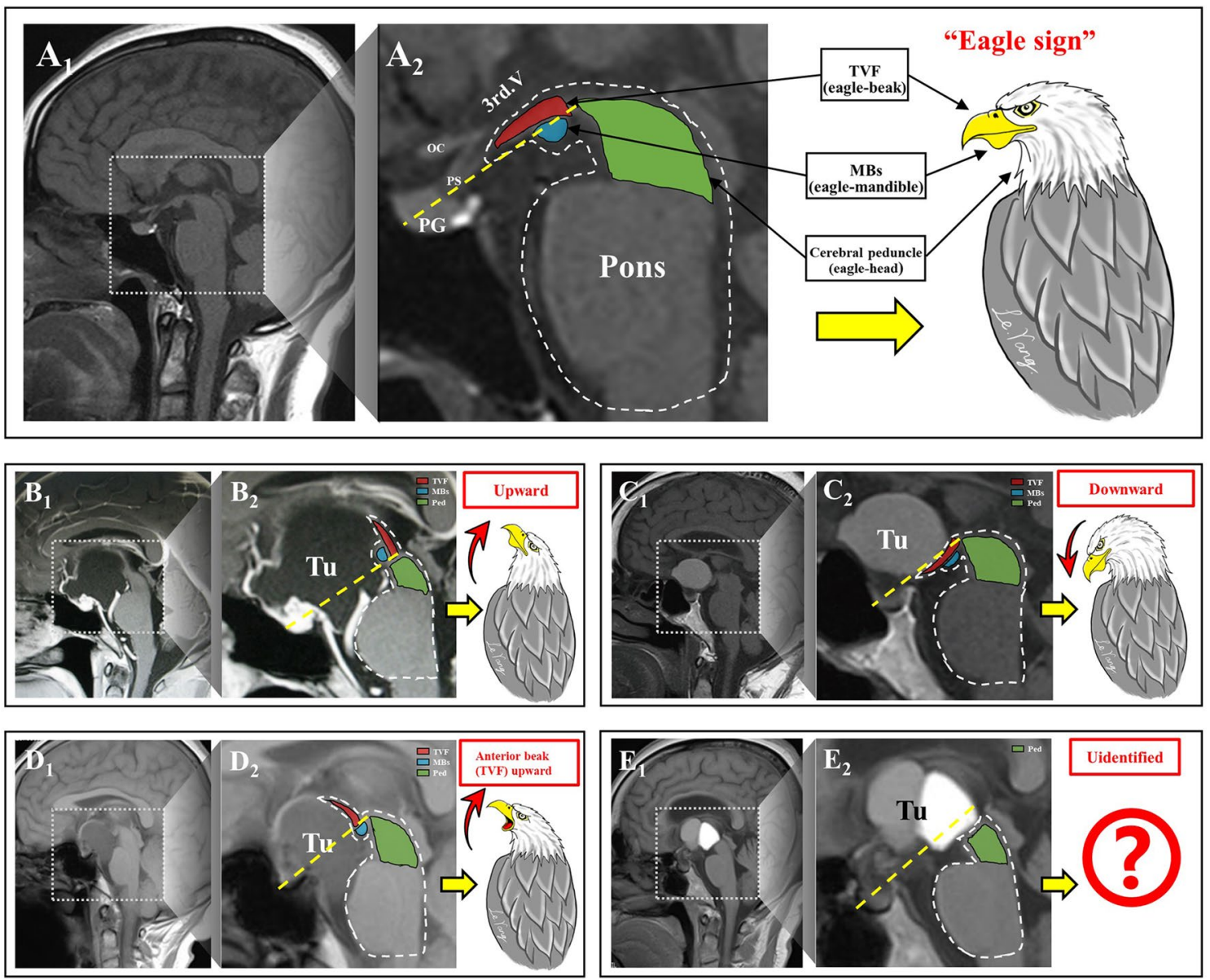

Fig. 1 Variable "eagle signs". $\mathrm{A}_{1-2}$ The "eagle sign" is formed by TVF, MBs and Ped. The TVF (red color) was represented as the beak, the MBs (blue color) as the mandible and the Ped (green color) as the eagle-head. The normal TVF is defined as the connection between the terminal of cerebral peduncle and the frontal onethird part of sella turcica (the yellow dotted line) for the baseline. $\mathrm{B}_{1-2}$ Upward sign, both the beak and the mandible of the "eagle sign" are facing upward compared with the normal TVF line. $\mathrm{C}_{1-2}$ Downward "eagle sign", both the beak and mandible of the "eagle sign"

are facing downward. $\mathrm{D}_{1-2}$ Anterior beak upward sign, the anterior beak (anterior TVF, infundibulotuberal area, anterior to the MBs) of the "eagle sign" is facing upward with posterior beak (posterior TVF) and the mandible (MBs) showing normal state or facing downward. $\mathrm{E}_{1-2}$ Unidentified sign, the "eagle sign" and the posture of the eaglehead cannot be identified on all MR images. TVF third ventricle floor, $M B s$ mamillary bodies, $P e d$ cerebral peduncle, $O C$ optic chiasma, $P G$ pituitary gland, $3 r d . V$ third ventricle, $T u$ tumor

Publisher's Note Springer Nature remains neutral with regard to jurisdictional claims in published maps and institutional affiliations. 